\title{
Reconstructing predation intensity on crinoids using longitudinal and cross-sectional approaches
}

\author{
Tomasz K. Baumiller $^{1}$ (D) $\cdot$ Angela Stevenson $^{2}$
}

Received: 25 August 2018/Accepted: 27 September 2018/Published online: 12 October 2018

(C) Akademie der Naturwissenschaften Schweiz (SCNAT) 2018

\begin{abstract}
Predation has been hypothesized as important to crinoid ecology, and numerous crinoid traits have been linked to predation. However, testing such hypotheses requires some assessment of predation intensity, or pressure. Although direct observations of predatory activity on crinoids are exceedingly rare in the Recent, and unobservable in the fossil record, evidence of predation exists in the form of sublethal damage, especially to their arms. Substantial data exist on the relative frequency, or prevalence, of such injuries, but estimating predation intensity in taxa with ephemeral injuries, such as crinoids, requires combining the prevalence of injuries with rates at which they heal (regenerate). An alternate, independent estimate of predation intensity involves gathering longitudinal data on the number of injuries incurred by particular individuals over a given time span. In this study, predation intensity on crinoids is explored experimentally using these two approaches. We demonstrate that for the two feather star species examined, Capillaster multiradiatus and Clarkcomanthus mirabilis, both methods produce reasonably consistent results and that predation intensity is slightly lower on the latter perhaps because it responds to tactile stimulation by crawling deeper into its perch, whereas the former shows no response.
\end{abstract}

Keywords Regeneration rate $\cdot$ Prevalence of injuries · Feather stars

\section{Introduction}

Arm injuries are a common feature of extant and fossil crinoids (e.g., Baumiller and Gahn 2004, 2013; Gahn and Baumiller 2005, 2010; Mladenov 1983; Meyer 1985; Meyer and Oji 1993; Oji 1996, 2001; Oji and Okamoto 1994; Schneider 1988; Strimple and Beane 1966). Crinoid arm loss may be a consequence of abiotic stresses such as rapid changes in salinity or temperature (Baumiller 2003), and some taxa are known to autotomize arms during ontogeny (Clark 1910; Emson and Wilkie 1980; Minckert 1905; Roux 1976; Shibata and Oji 2005). However, most arm injuries in crinoids are thought to result from fish predatory attacks

Editorial Handling: D. Marty.

Tomasz K. Baumiller

tomaszb@umich.edu

1 Museum of Paleontology, Department of Earth and Environmental Sciences, University of Michigan, Ann Arbor, MI 48109, USA

2 Department of Zoology, University of British Columbia, Vancouver, BC V6T 1Z4, Canada
(Meyer 1985; Meyer et al. 1984), though other taxa may also play a role (Baumiller et al. 2008, 2010; Brun 1972; Mladenov 1983; Gorzelak et al. 2012). The prevalence of crinoid arm injuries, herein defined as the relative frequency of individuals with injured arms, has received considerable attention and is generally thought to be substantial. For example, Meyer (1985) found that, among 10 Great Barrier Reef feather star species, the relative frequency of individuals with injured arms, ranged from 0.23 to 0.77 . Schneider's (1988) survey of Pacific and West Atlantic feather stars revealed that over 0.30 of individuals were injured, with all individuals (1.00) injured in some species. Baumiller and Gahn (2013) reported that all individuals of the feather star Cenometra bella from Palau had at least one injured arm. Prevalence of injuries has also been reported for a few deepwater crinoids, such as isocrinids (Oji 1996: ca. 0.70) and cyrtocrinids (Syverson et al. 2015: ca. 0.10).

Injuries have also been recognized in fossil crinoids (Foerste 1893; Hall 1861; Wachsmuth and Springer 1897; Whitfield 1904), but these have been examined systematically only recently (see Baumiller and Gahn 2003, 2004, 2013; Meyer and Ausich 1983; Meyer and Oji 1993; Oji 2001; Weissmüller 1998). Prevalence of arm 
injuries found in Paleozoic crinoids can reach as high as 0.12 among some crinoid faunas, with individual species as high as 0.27 (Baumiller and Gahn 2004; Gahn and Baumiller 2005), whereas Mesozoic and Cenozoic faunas reveal lower values (Meyer and Oji 1993; Weissmüller 1998). Baumiller and Fordyce (2018) reported the only record of an injured fossil feather star known to us, which may not reflect the rarity of injuries so much as the extreme rarity of even partially intact feather star fossils.

Since crinoid arm injuries have been primarily ascribed to predation, their high prevalence among extant faunas has been interpreted as a consequence of high predation intensity, which, in turn, has been invoked as causally linked to many morphological, ecological, and behavioral characteristics of extant crinoids. Among the latter are (1) the nocturnal and swimming behavior of feather stars (Meyer and Macurda 1977), (2) the development of articulations specialized for autotomy that allow crinoids to "shed" their arms (Oji and Okamoto 1994) and distal portion of the stalk (Baumiller et al. 2008), (3) the autotomy and rapid regeneration of the visceral mass (Meyer 1988), (4) the evolution of robust oral pinnules that serve to protect the tegmen (Meyer 1985), and (5) the unusually prolonged gamete production and storage (Nichols 1996).

The use of the prevalence of injuries, also referred to as regeneration frequency, as a proxy for predation intensity has often been employed in the study of other extant and fossil echinoderms as well as crinoids. Since prevalence is the relative frequency of injured individuals (or injured arms) in a population at a given time, it is relatively easy to measure via in situ surveys of live organisms or by examining specimens from single localities representing snapshots of a population preserved at some instant in time. Because studies of injuries in fossil echinoderms require exceptional preservation of many individuals with articulated arms, echinoderm Lagerstätten have been used as the source of data for estimates of injury prevalence (e.g., Aronson 1987, 1991; Baumiller and Gahn 2004).

While data on prevalence of injuries are relatively easy to acquire, their use as a proxy for predation intensity is not straight-forward. For example, Schoener (1979) showed theoretically that for injuries that leave detectable scars throughout life, prevalence of injuries in a population "measures the inefficiency of predation, not its intensity" (p 1112, Schoener 1979) where "inefficiency of predation" is the probability of surviving a predatory encounter (dimensionless) and predation intensity is the encounter rate between prey and predator (dimensions of $\mathrm{t}^{-1}$ ). Because echinoderms have exceptional regenerative abilities, arm injuries are ephemeral and leave no detectable signature. As a result, Baumiller $(2013 \mathrm{a}, \mathrm{b})$ argued that predation intensity is a function of prevalence of injuries and injury healing time (Baumiller 2013a, b). It follows that the relationship between predation intensity when fatalities from such incidents are low, e.g., for partial or cropping predation characteristic of crinoids and other echinoderms, can be expressed by the following equation:

$i=-\frac{\ln (1-P)}{\mathrm{Th}}$

where $i$ is predation intensity (dimensions of $\mathrm{t}^{-1}$ ), $P$ is the prevalence of injuries (relative frequency of injured individuals in a population, dimensionless), and Th (dimensions of $\mathrm{t}$ ) represents the amount of time to fully heal, when any directly visible record of the injury disappears; Th is directly proportional to the length of the lost arm ( $L_{\mathrm{arm}}$, dimensions of 1) and inversely proportional to the rate of arm regeneration ( $\mathrm{AR}$, dimensions of $\mathrm{lt}^{-1}$ ). Equation 1 suggests that an estimate of predation intensity requires some knowledge of prevalence of injuries and the time it takes for injuries to heal.

Whereas the above equation allows one to calculate predation intensity, $i$, indirectly from $P$ and Th, it is also possible to estimate predation intensity more directly by monitoring the number of injuries incurred by individuals over some interval of time. Since the latter approach requires solely longitudinally obtained data, we will refer to it as the "longitudinal approach", whereas we will refer to the approach governed by Eq. 1 as "cross-sectional" because it utilizes cross-sectionally obtained values of $P$ (as well as longitudinal obtained data on Th).

To our knowledge, the longitudinal approach has not been tried with crinoids. This study proposes to employ both approaches by gathering temporally and spatially constrained observations and conducting field experiments to obtain values of relevant parameters to calculate predation intensity on two feather stars.

\section{Materials and methods}

\section{Field site}

Six underwater locations in Malatapay coral reef (9.121521, - 236.785946), Negros Oriental, The Philippines, were selected and marked with underwater floats (to facilitate feather star recovery) at increments of 5-m depth intervals between 5 and $30 \mathrm{~m}$ using SCUBA.

\section{Arm regeneration rates}

A total of 21 adult individuals of Capillaster multiradiatus $(N=12)$ and Clarkcomanthus mirabilis $(N=8)$ (both family Comatulidae) found perched on sponges, corals (living and dead), and rocks were randomly selected for the study (Fig. 1). Several arms were amputated from each 
individual by holding an arm until it was released (autotomized); following this procedure, the individual was replaced on its original perch near the site marker.

To facilitate recovery and identification, multiple (3-7) adjacent arms were amputated on each individual in a unique pattern, and oral and aboral sides of each individual were photographed for identification. Regenerating arms were photographed ca. once monthly for a maximum of 4 months alongside a scale bar. Regenerating arm length and maximum arm length were calculated using the 'segments' function in ImageJ version 1.47 (Schneider et al. 2012). Regeneration rates were calculated for each regenerating arm on each individual by dividing the change in length by elapsed time, such that for Capillaster multiradiatus 141 independent arm regeneration rates were obtained from 12 individuals; for Clarkcomanthus mirabilis 96 rates were obtained from 8 individuals. For each species regeneration rate was calculated as the average of all independent rates for that species.

\section{Arm lengths}

Unlike many other Comatulidae, in which anterior arms are markedly longer than posterior arms, both Capillaster multiradiatus and Clarkcomanthus mirabilis have uninjured arms of relatively similar lengths. Nevertheless, arms varied in length as nearly all individuals had some missing/ regenerating arms. In a fully developed individual, it is the longest arm that approximates the limit of arm growth and this is the value we expect injured arms to achieve after healing. We gathered data on arm lengths $\left(L_{\text {arm }}\right.$, dimensions 1) in $C$. multiradiatus $(N=17)$ and $C$. mirabilis $(N=13)$ by measuring the longest arm in randomly selected individuals of each species.

\section{Prevalence of injuries (relative frequency of injured individuals in the population)}

The relative frequency of injured individuals in $C$. multiradiatus $(N=324)$ and $C$. mirabilis $(N=50)$ was quantified from surveys conducted March 12-24th, 2017 on Malatapay reef. All surveys were conducted between 5 and $17 \mathrm{~m}$ depth. The number of injured individuals was quantified from photographs of the entire body taken during the survey (Fig. 2). Any individual with a regenerating or recently autotomized arm was categorized as "injured"; regeneration was recognized by an abrupt change in arm diameter.
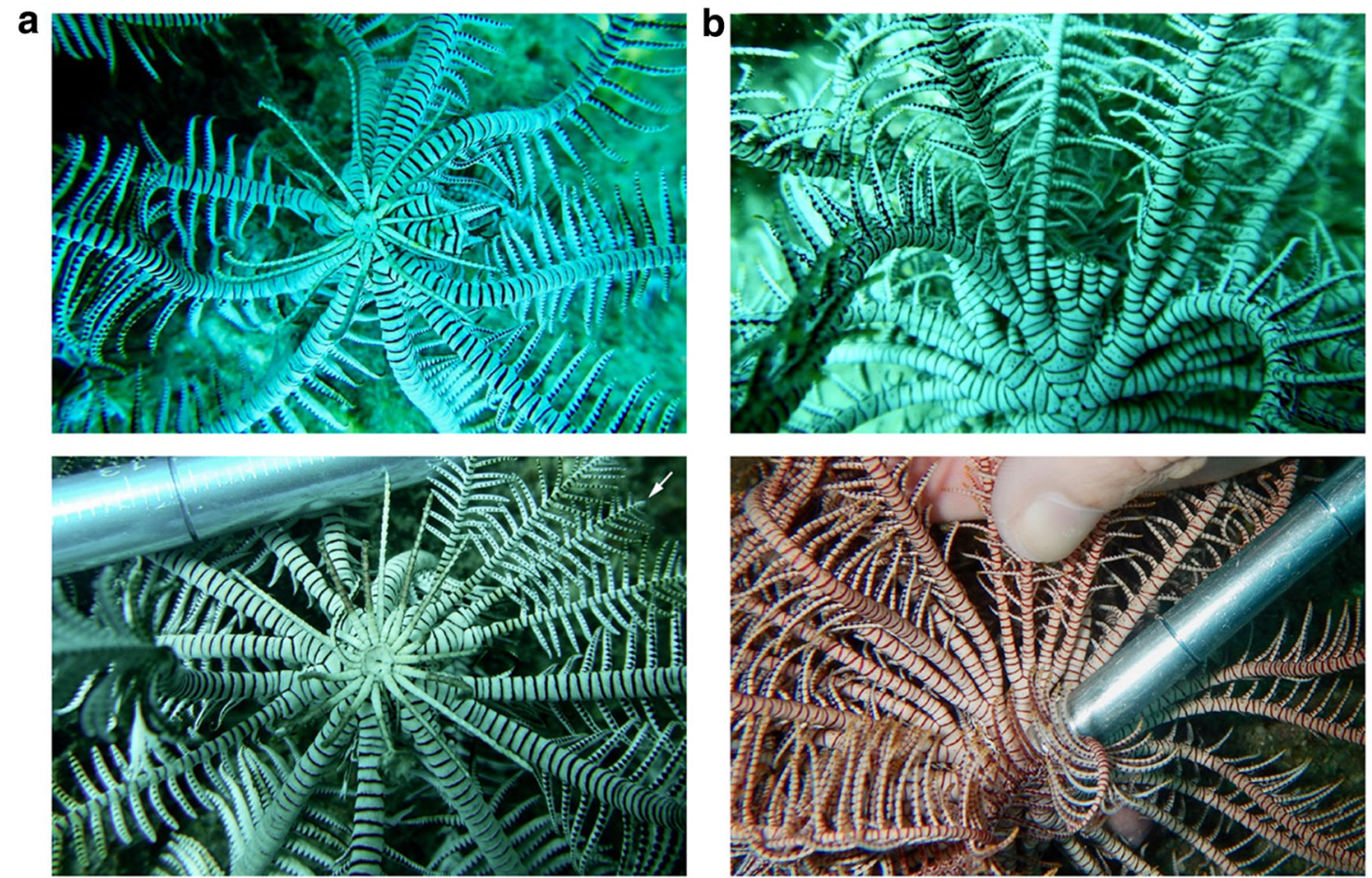

Fig. 1 Examples of amputated (top row) and regenerated (bottom row) arms of Capillaster multiradiatus (a) and Clarkcomanthus mirabilis (b) from Malatapay reef. Left column a: C. multiradiatus. The top photo is from the day of amputation, December 16, 2016; the bottom photo is from January 23, 2017. The length of the regenerated

arm (arrow) is $18.6 \mathrm{~mm}$. Right column $\mathbf{b}$ : C. mirabilis. The top photo is from the day of amputation, December 15, 2016; the bottom photo is from April 19, 2017. In the bottom photo, the tips of the 4 regenerated arms are obstructed by investigator's fingers 


\section{Predation intensity (arm loss events) from longitudinal data only}

All work was conducted in situ and without cages, allowing predatory activity to take place on unconfined amputees. Individuals were inspected for injuries prior to amputation; any initial injury/regeneration was noted for future record. Photographs from successive observations were compared, and any new arm injuries incurred between observations were recorded. A total of 66 observations were made between December 14th, 2016 and April 18th, 2017. The average time between observations was 23.5 days ( $\mathrm{SD}=$ 9.7 days). No injuries were recorded in 44 of those observations; newly injured arms were found in 22 observations. Among the latter, 14 observations involved a single injured arm, whereas more than 1 arm was found to be injured in 8 observations. To convert those observations to "events" of arm loss, a single injured arm was treated as a single event, but observations involving multiple arms had to be treated differently because adjacent regenerating arms of the same diameter could represent a single event or several events occurring in rapid succession. We chose to "split the difference" and treat them in the following way: if $x$ adjacent injured arms were of the same diameter, we estimated the number of events by $(x+1) / 2$. Observed predation intensity, $i_{\text {long }}$, was calculated for each species by dividing the total number of events incurred by all specimens by the total elapsed time for all specimens of each species.

\section{Results}

Table 1 summarizes the results. Arm regeneration rates of Capillaster multiradiatus $(0.55 \mathrm{~mm} /$ day $)$ and Clarkcomanthus mirabilis $(0.63 \mathrm{~mm} /$ day $)$ are statistically indistinguishable, whereas injured individuals are significantly more common in Capillaster multiradiatus (0.95) than in
Clarkcomanthus mirabilis $(0.82)(p<0.01$ using a Chisquared test). Longitudinally derived predation intensity, $i_{\text {long }}$, suggests that Capillaster multiradiatus (0.022 injuries per day) experiences a higher rate of arm loss than does Clarkcomanthus mirabilis (0.016 injuries per day). It may be more intuitive to consider arm loss rates in terms of the waiting time between arm loss events which are calculated by taking the reciprocals of $i_{\text {long. }}$. However, the averages, 45 days for $C$. multiradiatus and 62 days for C. mirabilis, are not statistically different.

The prevalence of injuries, $P$, the rate of arm regeneration, AR, and arm lengths, $L_{\text {arm }}$, allow us to estimate predation intensity, $i$, using Eq. 1 ; we use the subscript $i_{\text {cross }}$ to distinguish this value from $i_{\text {long. }}$. Clarkcomanthus mirabilis has significantly longer arms than Capillaster multiradiatus (132 mm vs. $104 \mathrm{~mm}$, respectively, $p<0.001$ using $t$ test). The amount of arm lost is in part controlled by the distribution of arm articulations specialized for autotomy (syzygies), and these are distributed throughout the length of feather star arms (Oji and Okamoto 1994). Although the interval between syzygies on the arms of $C$. multiradiatus (6-8 articulations) is greater than in C. mirabilis (3-5 articulations), the shorter brachials of $C$. multiradiatus produce a similar number of syzygies for arms of similar length (Messing personal communication). Our observations of arm injuries indicate that in both species arm injuries are found on the proximal part of the arm (Fig. 2), so in calculating $\mathrm{Th}$, we assumed that on average $C$. multiradiatus and $C$. mirabilis lose $3 / 4$ of the length of an arm during a predatory event ( $\left.\mathrm{Th}=0.75 \mathrm{~L}_{\mathrm{arm}} / \mathrm{AR}\right)$.

The calculated values of $i_{\text {cross }}$ (Table 1) indicate that Capillaster multiradiatus (0.024 injuries day $^{-1}$ ) experiences a significantly higher rate of injuries $(p<0.001$ using 1000 simulations) than does Clarkcomanthus mirabilis (0.012 injuries day $\left.{ }^{-1}\right)$; in terms of the waiting time between injuries, these average 41 days and 83 days for the two taxa, respectively.

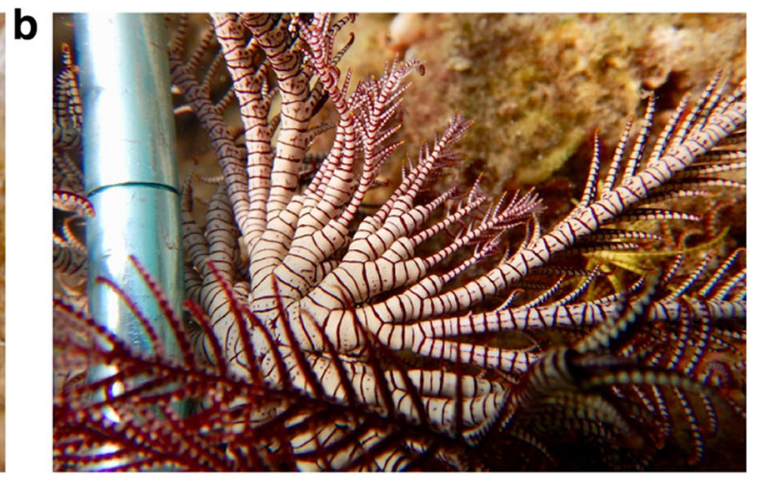

Fig. 2 Examples of injured individuals of Capillaster multiradiatus (a) and Clarkcomanthus mirabilis (b) from surveys of Malatapay reef conducted March 12-24th, 2017 
Table 1 Experimental and observational data for Capillaster multiradiatus and Clarkcomanthus mirabilis gathered at six underwater locations in Malatapay coral reef $(9.121521,-236.785946)$, Negros Oriental, The Philippines

\begin{tabular}{lll}
\hline & $\begin{array}{l}\text { Capillaster } \\
\text { multiradiatus }\end{array}$ & $\begin{array}{l}\text { Clarkcomanthus } \\
\text { mirabilis }\end{array}$ \\
\hline A. Arm regeneration rate (AR) ns (mm/day) & 0.55 & 0.63 \\
SD (mm/day) & 0.27 & 0.48 \\
$N$ (\# independent measurements) & 141 & 96 \\
$N$ (\# individuals) & 12 & 8 \\
B. Arm length $\left(L_{\text {arm }}\right.$ )*** $(\mathrm{mm})$ & 104 & 132 \\
SD (mm) & 19 & 19 \\
$N$ (\# individuals) & 17 & 13 \\
C. Prevalence of injuries $(P) * *$ & 0.95 & 0.82 \\
SD & 0.01 & 0.06 \\
$N$ (\# individuals) & 324 & 50 \\
D. Predation intensity “longitudinal” $(i)$ ns (injuries/day) & 0.022 & 0.016 \\
SD (injuries/day) & 0.020 & 0.015 \\
$N$ (\# individuals) & 13 & 5 \\
E. Predation intensity “cross sectional” $(i) * *$ (injuries/day) & 0.024 & 0.012 \\
SD (injuries/day) & 0.003 & 0.004 \\
\hline
\end{tabular}

$n s$ no significant difference between $C$. multiradiatus and $C$. mirabilis

**Values for $C$. multiradiatus and $C$. mirabilis are significantly different $(p<0.01)$

***Values for $C$. multiradiatus and $C$. mirabilis are significantly different $(p<0.001)$

\section{Discussion and conclusions}

The results of this study provide data on crinoid ecology and physiology that are either new or have been previously reported only rarely. Published data on arm regeneration rates include two studies, one by Mladenov (1983) on the feather star, Florometra serratissima, and the other by Syverson et al. (2015) on the cyrtocrinid, Holopus mikihe. The arm regeneration rate for $F$. serratissima (ca. $0.5 \mathrm{~mm} \mathrm{day}^{-1}$ ) (Mladenov 1983) is very similar to rates for C. multiradiatus and C. mirabilis despite its occurrence at much lower temperatures and greater depth $(25 \mathrm{~m})$ near Bamfield Marine Station, Barkley Sound, British Columbia. By comparison, the regeneration rate of Holopus mikihe from a depth ca. $500 \mathrm{~m}$ was $0.017 \mathrm{~mm} \mathrm{day}^{-1}$, or roughly 30 times lower than the feather star rates. These differences may reflect a strong phylogenetic signal or factors associated with bathymetry, but without more data we cannot explore this issue further.

As mentioned in the Introduction, numerous studies have focused on prevalence of injuries in extant and fossil crinoids, and the results for Capillaster multiradiatus (0.95) and Clarkcomanthus mirabilis (0.82) fall within the range of previously reported values, although towards its upper end. Some comparisons are worth noting. For example, Mladenov (1983) reported a slightly lower value (0.80) for Florometra serratissima from Barkley Sound, whereas (Baumiller and Gahn 2013) noted a higher value for Cenometra bella (1.0) from the shallow reefs of Palau.
Relative to the 0.95 prevalence of injuries in C. multiradiatus at Malatapay, Meyer (1985) reported a strikingly lower value (0.29) for $C$. multiradiatus from the Great Barrier Reef. It is unclear whether this reflects fundamental differences between the two environments, physiological/ ecological differences between the two populations of an ecologically highly variable taxon (Messing and Tay 2016), or that this taxon consists of multiple species.

To our knowledge, no longitudinal study on the intensity of predation on crinoids has been reported; thus our data for Capillaster multiradiatus and Clarkcomanthus mirabilis are the first of this type. Both the longitudinally derived $\left(i_{\text {long }}\right)$ and cross-sectionally derived $\left(i_{\text {cross }}\right)$ predation intensities are higher in $C$. multiradiatus than $C$. mirabilis and may be due to slight differences in their behavior (Fig. 3). While our observations indicate that both C. multiradiatus and C. mirabilis perch completely in the open when feeding, C. multiradiatus often curls up in a tight ball on top of a coral or rubble when not feeding; it does not tend to take shelter as much as $C$. mirabilis and is thus easier to locate. Additionally, $C$. mirabilis responds to tactile stimulation by retreating further into crevices, coral branches, deeper under ledges, whereas $C$. multiradiatus shows no such response.

When comparing the two independently derived predation intensities, $i_{\text {cross }}$ and $i_{\text {long }}$ (Fig. 4), the longitudinally derived value for $C$. mirabilis is ca. $24 \%$ higher than the cross-sectionally derived value, whereas for $C$. multiradiatus the difference is ca. $11 \%$ lower. Given the intrinsic 
variability and measurement errors associated with each of the variables, the small differences seem surprising. This is especially so given that the cross-sectional approach does not differentiate between those individuals with single and multiple arm injuries, and the latter are relatively common in these two species. If every arm injury represents an independent event of arm loss, the cross-sectional predation intensity, $i_{\text {cross }}$, should underestimate the true intensity. One can calculate predation intensity assuming that every injured arm represents one event by the modifying Eq. 1 (Baumiller 2013a, b; Baumiller and Gahn 2013):

$i=-\frac{\ln \left(1-P_{\text {arms }}\right)}{\mathrm{Th}} \times N_{\mathrm{arms}}$,

where $P_{\text {arms }}$ is the prevalence of injured arms (relative frequency of injured arms in a population, dimensionless), $N_{\text {arms }}$ is the average number of arms per individual (dimensionless) and the other variables are as in Eq. 1. For Capillaster multiradiatus and Clarkcomanthus mirabilis, the prevalence of missing arms, $P_{\text {arms }}$, is 0.27 and 0.12 , respectively, and the former has an average of 17 arms while the latter 40 arms. Using Eq. 2, these values translate to predation intensities of 0.042 for $C$. multiradiatus and 0.036 for C. mirabilis (Fig. 4). As expected, cross-sectionally derived predation intensities assuming that each injured arm represents a predatory encounter are higher than those that assume all injured arms on a single
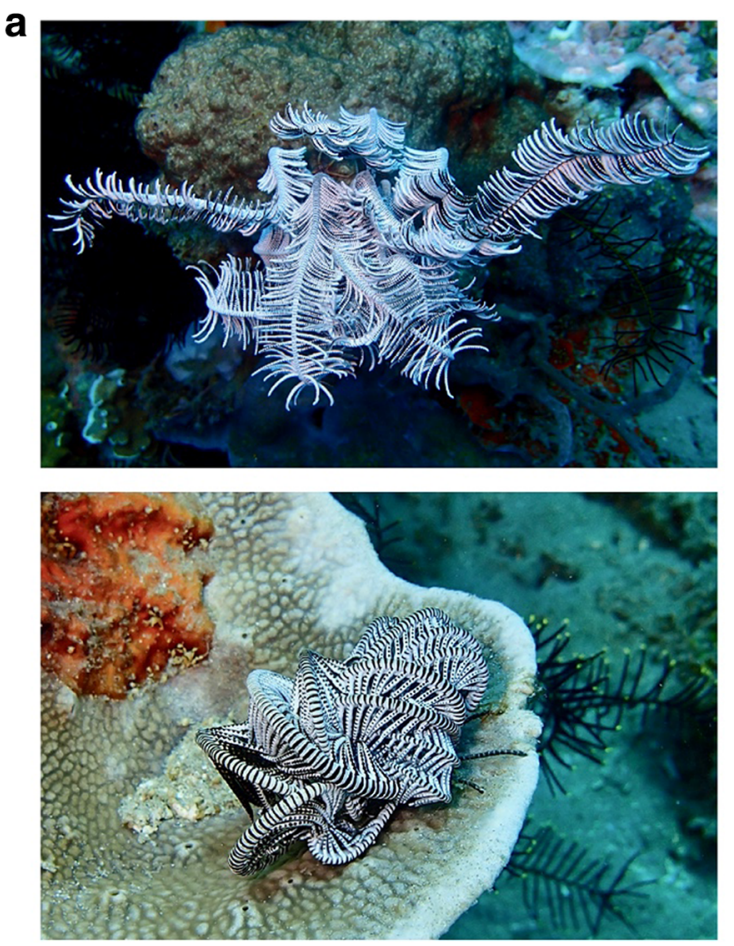

individual, regardless how many, represent just one encounter. It is likely that for both species true predation intensities lie somewhere between these two extremes, likely closer to longitudinally derived values which are based on a more detailed assessment of estimated events of predation intensity (see "Materials and methods"). The fact that the longitudinally derived values are much closer to cross-sectionally derived estimates, which treat multiple injuries on individuals as caused by single events, is consistent with our observations that for both species, multiple injuries are often found on adjacent arms and the similar size of their regenerating portions suggests that these arms were lost simultaneously, likely during a single encounter.

Whereas neontologists interested in predation intensity can employ the longitudinal or either of the cross sectional approaches, the task is much more difficult for paleontologists. The longitudinal approach cannot be employed with fossil crinoids, so the only alternative is the cross-sectional approach (Eqs. 1 and 2). As already mentioned, neontologists and paleontologists have been reporting cross-sectionally derived data on the prevalence of injuries in crinoids, but its use in estimating predation intensity is hampered by lack of data on healing rates (arm lengths and arm regeneration rates). Arm lengths are easily obtainable, but regeneration rates have been measured for very few taxa and environments. Whereas the regeneration rates reported in this study and in Mladenov (1983) indicate
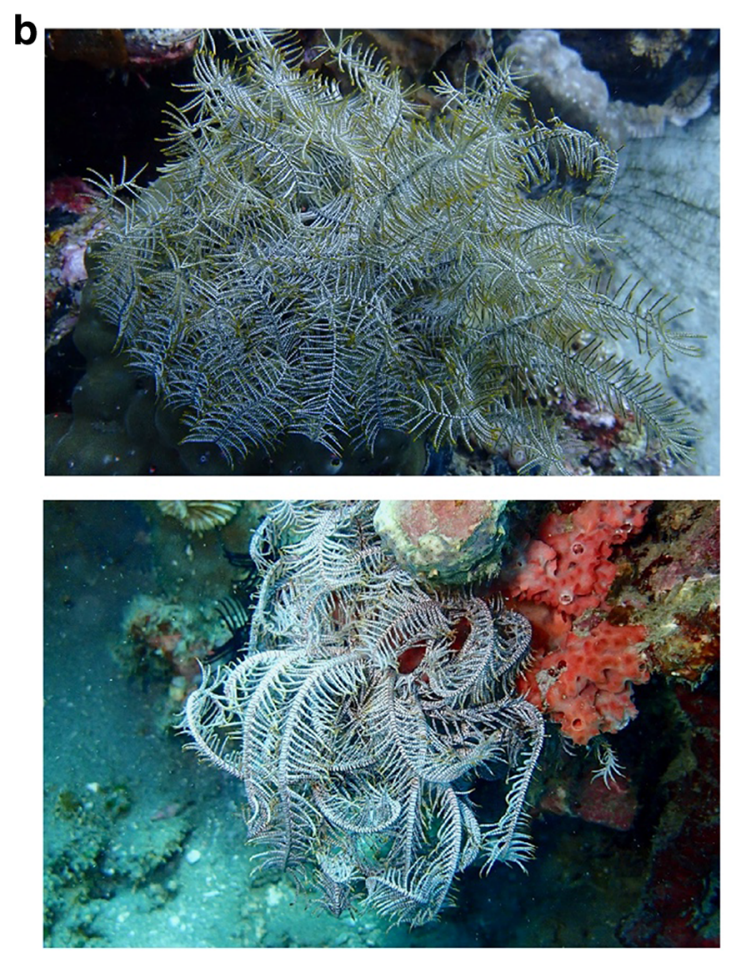

Fig. 3 Examples of feeding (top row) and resting (bottom row) postures of Capillaster multiradiatus (a) and Clarkcomanthus mirabilis (b) from Malatapay reef. The maximum arm length in Capillaster multiradiatus (a) is ca. $104 \mathrm{~mm}$ and Clarkcomanthus mirabilis (b) ca. $132 \mathrm{~mm}$ 


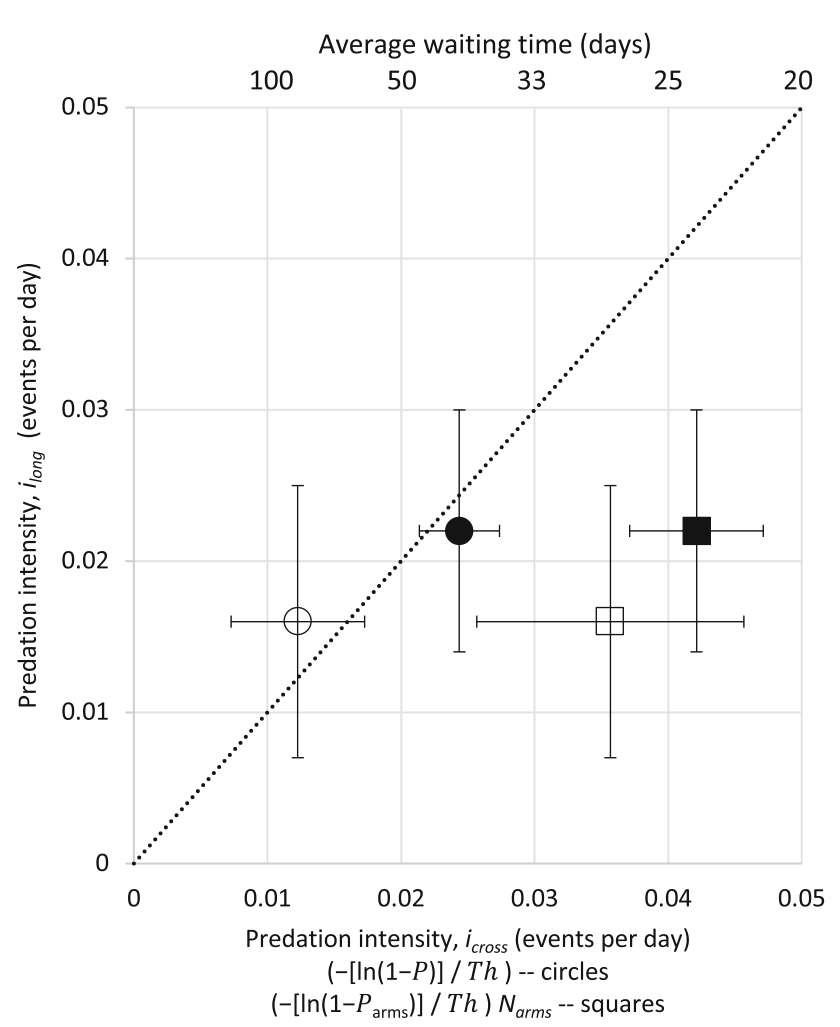

Fig. 4 Estimates of average predation intensity ( \pm 1 standard error) for two feather stars, Capillaster multiradiatus (solid symbols) and Clarkcomanthus mirabilis (open symbols) obtained using two independent approaches. Predation intensities, $i_{\text {cross }}$, plotted on the $x$-axis were obtained using Eq. 1 (circles) and Eq. 2 (squares), whereas $i_{\text {long }}$ on the $y$-axis were obtained using longitudinal data only. The dotted, diagonal line has a slope of 1 , thus for points falling on the line $i_{\text {long }}=i_{\text {cross }}$. The secondary $x$-axis (top) represents the average waiting time between injuries calculated as $1 / i$; a corresponding secondary $y$-axis is not labeled to avoid clutter

similar values for shallow water feather star species, ca. $0.5 \mathrm{~mm} \mathrm{day}{ }^{-1}$, the much lower regeneration rate reported by Syverson et al. (2015) for the deep-water cyrtocrinid, Holopus mikihe, suggests that these rates may vary widely across environments and/or higher taxa. Lacking data on regeneration rates, the use of injury prevalence alone as a predation intensity proxy can be quite misleading, as high prevalence could be a consequence of low predation intensity and long healing times or vice versa: high predation intensity and short healing time. Since data on regeneration rates cannot be obtained from fossil crinoids, paleontological studies of predation intensity will require assumptions based on rates from neontological studies, or comparative approaches in which regeneration can be assumed as invariant.

Acknowledgements This work would not have been possible without the dedicated efforts of Tadhg Ó Corcora in the field and Marine Conservation Philippines with logistics. The study was partly funded by the Challenger Society for Marine Sciences Stepping Stone Bursary to A. Stevenson. We appreciate the insightful comments from
Charles Messing and Tatsuo Oji that helped improve this manuscript. This contribution is dedicated to the memory of Hans Hess.

\section{References}

Aronson, R. B. (1987). Predation on fossil and Recent ophiuroids. Paleobiology, 13, 187-192.

Aronson, R. B. (1991). Predation, physical disturbance, and sublethal arm damage in ophiuroids: A Jurassic-Recent comparison. Marine Ecology Progress Series, 74, 91-97.

Baumiller, T. K. (2003). Experimental and biostratinomic disarticulation of crinoids: Taphonomic implications. In J.-P. Féral \& B. David (Eds.), Echinoderm research 2001 (pp. 243-248). Lisse: Balkema.

Baumiller, T. K. (2013a). Ephemeral injuries, regeneration frequencies and intensity of the injury-producing process. Marine Biology, 160, 3233-3239. https://doi.org/10.1007/s00227-0132302-9.

Baumiller, T. K. (2013b). Arm regeneration frequencies in Florometra serratissima (Crinoidea, Echinodermata): Impact of depth of habitat on rates of arm loss. Cahiers de Biologie Marine, 54, 571-576.

Baumiller, T. K., \& Fordyce, R. E. (2018). Rautangaroa, a new genus of feather star (Echinodermata: Crinoidea) from the Oligocene of New Zealand. Journal of Paleontology, 92(872), 882. https://doi. org/10.1017/jpa.2018.17.

Baumiller, T. K., \& Gahn, F. J. (2003). Chapter 10, predation on crinoids. In P. H. Kelley, M. Kowalewski, \& T. A. Hansen (Eds.), Predator-prey interactions in the fossil record. Topics in geobiology (Vol. 20, pp. 263-278). New York: Springer.

Baumiller, T. K., \& Gahn, F. J. (2004). Testing predation-driven evolution using Mid-Paleozoic crinoid arm regeneration. Science, 305, 1453-1455.

Baumiller, T. K., \& Gahn, F. J. (2013). Reconstructing predation pressure on crinoids: Estimating arm-loss rates from regenerating arms. Paleobiology, 39, 40-51.

Baumiller, T. K., Mooi, R., \& Messing, C. G. (2008). Urchins in the meadow: Paleobiological and evolutionary implications of cidaroid predation on crinoids. Paleobiology, 34, 22-34.

Baumiller, T. K., Salamon, M., Gorzelak, P., Mooi, R., Messing, C. G., \& Gahn, F. J. (2010). Benthic predation drove early Mesozoic crinoid radiation. PNAS, 107, 5893-5896.

Brun, E. (1972). Food and feeding habits of Luidia ciliaris (Echinodermata: Asteroidea). Journal of the Marine Biological Association of the United Kingdom, 52, 225-236.

Clark, A. H. (1910). The origin of the crinoidal muscular articulation. American Journal of Science, 29, 40-44.

Emson, R. H., \& Wilkie, I. C. (1980). Fission and autotomy in echinoderms. Oceanography and Marine Biology: An Annual Review, 18, 155-250.

Foerste, A. F. (1893). The reproduction of arms in crinoids. American Geologist, 12, 270-271.

Gahn, F. J., \& Baumiller, T. K. (2005). Arm regeneration in Mississippian crinoids: Evidence of intense predation pressure in the Paleozoic? Paleobiology, 31, 151-164.

Gahn, F. J., \& Baumiller, T. K. (2010). Evolutionary history of regeneration in crinoids (Echinodermata). Integrative and Comparative Biology, 50, 514a-514m. https://doi.org/10.1093/icb/ icq155.

Gorzelak, P., Salamon, M. A., \& Baumiller, T. K. (2012). Predatorinduced macroevolutionary trends in Mesozoic crinoids. PNAS, 109, 7004-7007. 
Hall, J. (1861). Description of new species of Crinoidea from the Carboniferous rocks of the Mississippi Valley. Journal of the Boston Society of Natural History, 7, 261-328.

Messing, C. G., \& Tay, T. S. (2016). Extant Crinoidea (Echinodermata) of Singapore. Raffles Bulletin of Zoology Supplement, 34, 627-658 D.

Meyer, D. L. (1985). Evolutionary implications of predation on Recent comatulid crinoids from the Great Barrier Reef. Paleobiology, 11, 154-164.

Meyer, D. L. (1988). Crinoids as renewable resources: Rapid regeneration of the visceral mass in a tropical reef-dwelling crinoid from Australia. In R. D. Burke, P. D. Mladenov, P. Lambert, \& R. L. Parsley (Eds.), Echinoderm biology (pp. 519-522). Rotterdam: A. A. Balkema.

Meyer, D. L., \& Ausich, W. I. (1983). Biotic interactions among Recent and fossil crinoids. In M. F. S. Tevesz \& P. L. McCall (Eds.), Biotic interactions in Recent and fossil benthic communities (pp. 377-427). New York: Plenum.

Meyer, D. L., LaHaye, C. A., Holland, N. D., Arenson, A. C., \& Strickler, J. R. (1984). Time-lapse cinematography of feather stars (Echinodermata: Crinoidea) on the Great Barrier Reef, Australia: Demonstrations of posture changes, locomotion, spawning and possible predation by fish. Marine Biology, 78, 179-184.

Meyer, D. L., \& Macurda, D. B., Jr. (1977). Adaptive radiation of comatulid crinoids. Paleobiology, 3, 74-82.

Meyer, D. L., \& Oji, T. (1993). Eocene crinoids from Seymour Island, Antarctic Peninsula: Paleobiogeographic and paleoecologic implications. Journal of Paleontology, 67, 250-257.

Minckert, W. (1905). Über Regeneration bei Comatuliden nebst Ausführungen über die Auffassung und Bedeutung der syzygieen. Archiv fur Naturgeschichte, 71, 163-244.

Mladenov, P. V. (1983). Rate of arm regeneration and potential causes of arm loss in the feather star Florometra serratissima (Echinodermata: Crinoidea). Canadian Journal of Zoology, 61, $2873-2879$.

Nichols, D. (1996). Evidence for a sacrificial response to predation in the reproductive strategy of the comatulid crinoid Antedon bifida from the English Channel. Oceanologica Acta, 19, 237-240.

Oji, T. (1996). Is predation intensity reduced with increasing depth? Evidence from the west Atlantic stalked crinoid Endoxocrinus parrae (Gervais) and implications for the Mesozoic marine revolution. Paleobiology, 22, 339-351.

Oji, T. (2001). Fossil record of echinoderm regeneration with special regard to crinoids. Microscopy Research and Technique, 55, $397-402$

Oji, T., \& Okamoto, T. (1994). Arm autotomy and arm branching pattern as anti-predatory adaptations in stalked and stalkless crinoids. Paleobiology, 20, 27-39.

Roux, M. (1976). Aspects de la variabilité et de la croissance au sein d'une population de la pentacrine actuelle: Annacrinus wyville thompsoni Jeffreys (Crinoidea). Thalassia Jugoslavica, 12, 307-320.

Schneider, J. A. (1988). Frequency of arm regeneration of comatulid crinoids in relation to life habit. In R. D. Burke, P. V. Mladenov, P. Lambert, \& R. L. Parsley (Eds.), Echinoderm biology (pp. 531-538). Rotterdam: Balkema.

Schneider, C. A., Rasband, W. S., \& Eliceiri, K. W. (2012). NIH Image to ImageJ: 25 years of image analysis. Nature Methods, 9, 671-675.

Schoener, T. W. (1979). Inferring the properties of predation and other injury-producing agents from injury frequencies. Ecology, 60, 1110-1115.

Shibata, T. F., \& Oji, T. (2005). Autotomy and arm number increase in Oxycomanthus japonicus (Echinodermata, Crinoidea). Invertebrate Biology, 122, 375-379.

Strimple, H. L., \& Beane, B. H. (1966). Reproduction of lost arms on a crinoid from Le Grand, Iowa. Oklahoma Geology Notes, 26, 35-37.

Syverson, V. J., Messing, C. J., Stanley, K., \& Baumiller, T. K. (2015). Growth, injury, and population dynamics in the extant cyrtocrinid Holopus mikihe (Crinoidea, Echinodermata) near Roatán, Honduras. Bulletin of Marine Science, 91, 47-61. https://doi.org/10.5343/bms.2014.1061.

Wachsmuth, C., \& Springer, F. (1897). The North American Crinoidea Camerata. Harvard College Museum of Comparative Zoology Memoir, 20(21), 1-897.

Weissmüller, A. (1998). Ein umfangreicher Fund von Encrinus liliiformis Lamarck im Oberen Muschelkalk (mo2) des Diemeltales (Nordhessen). Phillipia, 8, 245-270.

Whitfield, R. P. (1904). Notice of a remarkable case of reproduction of lost parts shown on a fossil crinoid. Bulletin American Museum Natural History, 20, 471-472. 